\title{
Methodology for calculating diesel SCR systems
}

\author{
Artem Blinov*, Nikolay Malastowski, and Leonid Myagkov \\ Bauman Moscow State Technical University, 2-ya Baumanskaya Street, 5, Moscow, Russia, 105005
}

\begin{abstract}
Selective catalytic reduction systems are widely applied as a NOX emission control technology in modern on- and off highway diesel engines. Considering the stringent limits of emission standards, they should ensure high rates of conversion efficiency. To achieve that at the design stage numerical modelling is used to optimize physical and chemical processes. New mathematical models and methods that can provide the reduction of calculation time and related costs keeping the acceptable level of prediction accuracy are desired. In this study a methodology for calculating SCR systems based on the use both of CFD models and simplified catalyst models are presented. The capabilities of the suggested numerical approach were demonstrated during the simulations of a SCR system where the influence of UWS injection angle on NOX reduction efficiency was investigated.
\end{abstract}

\section{Introduction}

The introduction of selective catalytic reduction (SCR) for exhaust gas emissions from vehicles has been one of the major technical achievements in conditions of emission limits tightening according to international standards. Today there are no independent ways to reduce NOx formation, only combination of in-cylinder [1-5] and aftertreatment techniques [6-9] allows improving its emission level (Table 1) [9].

Table 1. Aftertreatment systems used for compliance with the European emission standards.

\begin{tabular}{|c|c|c|c|}
\hline & $\begin{array}{c}\text { Euro } \\
\text { III }\end{array}$ & $\begin{array}{l}\text { Euro IV - } \\
\text { Euro V }\end{array}$ & Euro VI \\
\hline $\begin{array}{l}\text { Aftertreatm } \\
\text { ent systems }\end{array}$ & $\begin{array}{l}\text { None } \\
\text { required }\end{array}$ & $\begin{array}{l}\text { - } \mathrm{NO}_{\mathrm{X}} \text { control } \\
\text { through } \\
\text { vanadium- } \\
\text { based, open- } \\
\text { loop SCR } \\
\text { systems; } \\
\text { - PM control } \\
\text { through DOC. }\end{array}$ & $\begin{array}{c}-\mathrm{NO}_{\mathrm{X}} \text { control } \\
\text { through zeolite- } \\
\text { based, closed-loop } \\
\mathrm{SCR} \text { systems; } \\
-\mathrm{NH}_{3} \text { control } \\
\text { through ASC; } \\
\text { - PM control } \\
\text { through DOC and } \\
\text { DPF }\end{array}$ \\
\hline
\end{tabular}

The main idea of the SCR technology is introducing ammonia to react with $\mathrm{NO}_{\mathrm{x}}$ over a catalytic surface, producing $\mathrm{N}_{2}$ and $\mathrm{H}_{2} \mathrm{O}$. The whole process can be summarized by two major stages [10]. At the first stage the ammonia is supplied to a SCR system in the form of urea-water-solution (UWS) injected and decomposed to $\mathrm{NH}_{3}$ in the exhaust pipe. At the second stage, the $\mathrm{NH}_{3}$ inside the catalyst is adsorbed on the catalyst substrate and catalytically reacts with $\mathrm{NO}_{\mathrm{X}}$ converting them to nitrogen $\mathrm{N}_{2}$ and water.

Nowadays using numerical methods widely spread along with the experimental works. The main their advantage is possibility to reduce overall design time without any additional costs. The state of the art for the
SCR aftertreatment systems design process is as two stage numerical technique combines 3D CFD models for the injection of UWS solution and 1D models for catalyst [11].

Taking into account this reason in the same time it is an obviously wish for development engineers using more accurate models with more different independent variables. Dimensions and layout of a SCR system, the catalyst characteristics, the UWS injection strategy that provide required conversion efficiency all of them are desirable to gain on the earlier stages of IC engines design process. From this point of view improving the existed models and optimizing model coupling lets to design SCR system efficiency

Extending the well-known 1D single-channel approach $[12,13]$ both for heat transfer between the channels and distributions of gas flow parameters at catalyst inlet is a one of the ways for improvement these models.

\section{Mathematical models}

Schematic representation of the developed methodology for calculating SCR systems is shown on Figure 1. It consists of two sequential simulation steps:

- CFD modelling of the gas flow dynamics throughout the SCR system and of the UWS injection, evaporation and decomposition.

- simulation of physical and chemical processes occurring in a SCR catalyst using simplified semi-1D catalyst model.

* Corresponding author: as blinov@bmstu.ru 


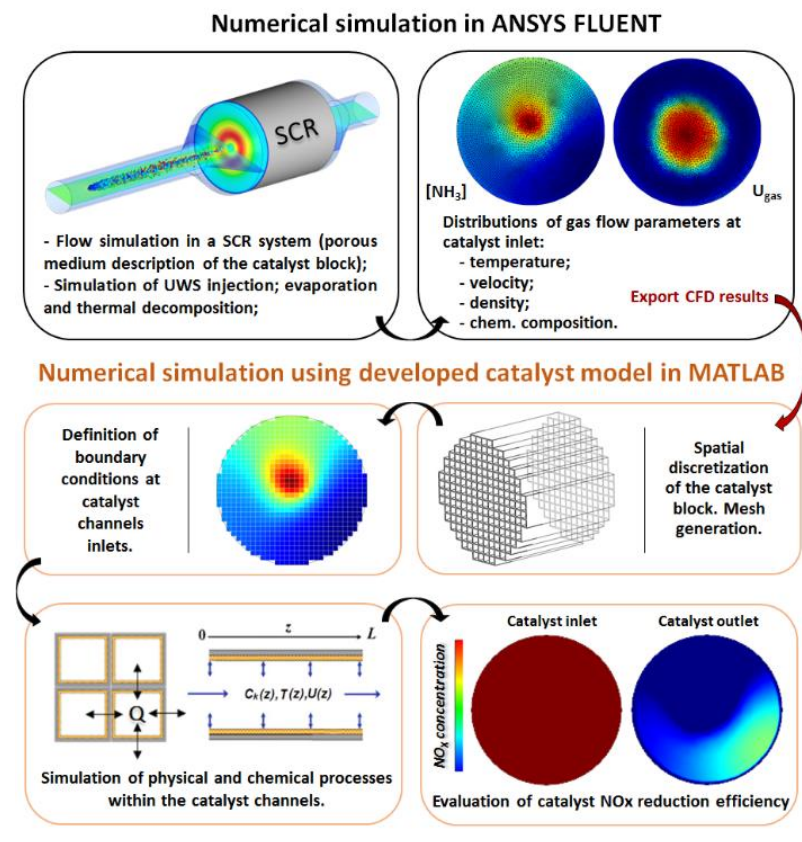

Fig. 1. Methodology for calculating SCR systems.

\subsection{D CFD modelling}

The purpose of this simulation step is to obtain distribution of flow parameters at catalyst inlet (temperature, velocity, chemical composition etc.). In this study ANSYS Fluent CFD software is used.

The flow simulation is performed using RANS formulation where Realizable $\mathrm{k}-\varepsilon$ model is adopted for turbulence closure. In the near-wall region flow is specified by the Enhanced Wall Treatment Model that combines two-layer approach with enhanced wall functions [14].

Due to a specific configuration the flow-through catalyst block is described as a porous medium. The pressure drop inside the channels caused by viscous and inertial losses is calculated in the following manner:

$$
\Delta p=C_{v i s c} \mu \cdot u \cdot z+\frac{\rho}{2} C_{i n e r t} u^{2} \Delta z
$$

where $C_{\text {visc }}, C_{\text {inert }}-$ viscous and inertial resistance coefficients, respectively.

The urea-water-solution spray is simulated within the Lagrangian approach. It was represented as a set of discrete droplets which trajectories were further tracked. An in-built Discrete Phase Model was applied. Initial droplet sizes and speeds as well as spray pattern are specified directly. The former is expressed in the form of Rosin-Rammler distribution function:

$$
Q(d)=1-\exp \left[-(d / \bar{d})^{n}\right.
$$

where $d$-droplet diameter, $\bar{d}$ - mean droplet diameter; $n$ - shape parameter of the distribution.

The secondary droplet breakup is simulated by the TAB model based on the analogy between an oscillation droplet and a spring mass system [15]. The droplet breakup is occurred when the displacement of droplet equator exceeds its critical value $(\mathrm{y}>1)$. It is calculated from the equation governing a damped, forced oscillator and in the nondimensional form is written as:

$$
\frac{C_{F} \rho_{g} u^{2}}{C_{b} \rho_{l} r^{2}}-\frac{C_{k} \sigma}{\rho_{l} r^{3}} y-\frac{C_{d} \mu_{l}}{\rho_{l} r^{2}} \&
$$

where $C_{F}, C_{b}, C_{k}, C_{d}-$ dimensionless constants; $\rho_{l}, \rho_{g}$ the discrete phase and continuous phase densities; $u$ relative velocity of the droplet; $r$ - undisturbed droplet radius; $\sigma$ - droplet surface tension; $\mu_{l}$ - droplet viscosity; $y$ - nondimensional droplet distortion.

The injected UWS droplets undergo heating and evaporation. The energy balance equation includes heat transferred to the droplet surface by convection from the surroundings, sensible heat and the latent heat required for vaporization [16]:

$$
Q_{\text {sens. }}=Q_{\text {conv. }}-Q_{\text {lat. }}
$$

$$
m_{d} c_{p d} \frac{d T_{d}}{d t}=h A_{d}\left(T_{\infty}-T_{d}\right)-\sum_{i} \frac{d m_{i}}{d t}\left(h_{\text {evap }, i}\right)
$$

where $Q_{\text {sens. }}$ - sensible heat; $Q_{\text {conv. }}$ - heat transferred by convection; $Q_{\text {lat. }}$ - latent heat of vaporization; $m_{d}-$ droplet mass; $c_{p d}-$ droplet specific heat capacity; $A_{d}$ droplet surface area; $h$ - heat transfer coefficient; $T_{d}-$ droplet temperature; $m_{i}-$ mass of an individual component; $h_{\text {evap }}$ - latent heat of vaporization; $T_{\infty}$ temperature in the bulk gas; $t$ - time.

The evaporation of UWS droplets was computed using multicomponent approach where the total rate of mass transfer was represented as a sum of rates of individual components. The latter was calculated by convection-diffusion model with the following equation [16]:

$$
\frac{d m_{d}}{d t}=\sum_{i} \frac{d m_{i}}{d t}=\sum_{i} A_{d} k_{c, i} \rho_{\infty} \ln \left(1+B_{m, i}\right)
$$

where $k_{c}$ - mass transfer coefficient; $\rho_{\infty}$ - bulk gas density; $B_{m, i}$ - Spalding mass transfer number.

The temperature and components concentration were assumed spatially uniform within the droplet but temporally varying.

The urea decomposition process was described by volumetric reactions where reaction rates were computed in accordance with power-law kinetic equations [17]:

Urea thermolysis:

$$
\begin{gathered}
\mathrm{CO}\left(\mathrm{NH}_{2}\right)_{2} \rightarrow \mathrm{NH}_{3}+\mathrm{HNCO} \\
R_{t h}=A_{t h} \cdot \exp \left(-\frac{E_{a, t h}}{R T}\right) \cdot\left[\mathrm{CO}\left(\mathrm{NH}_{2}\right)_{2}\right]
\end{gathered}
$$

Isocianic acid hydrolysis: 


$$
\begin{gathered}
\mathrm{HNCO}+\mathrm{H}_{2} \mathrm{O} \rightarrow \mathrm{NH} 3+\mathrm{CO}_{2} \\
R_{\text {hyd }}=A_{\text {hyd }} \cdot \exp \left(-\frac{E_{a, h y d}}{R T}\right) \cdot[H N C O]
\end{gathered}
$$

where $R_{i}$ - reaction rate; $A_{i}$ - pre-exponential constant; $E_{a, i}$ - activation energy; $R$ - universal gas constant; $T-$ gas temperature.

The kinetic parameters of reaction rates were defined based on the literature data [16].

\subsection{Models coupling}

The distributions of flow parameters at catalyst inlet (temperature, velocity, chemical composition etc.) obtained through CFD simulations are exported to the developed mathematical model implemented in MATLAB. They are used to define input boundary conditions of each catalyst channel. For that purpose, the following procedure is applied (Fig. 2):

- the generation of mesh representing substrate cross section;

- the interpolation of CFD data at mesh nodes;

- the arithmetic averaging of interpolated values within the channels inlets.

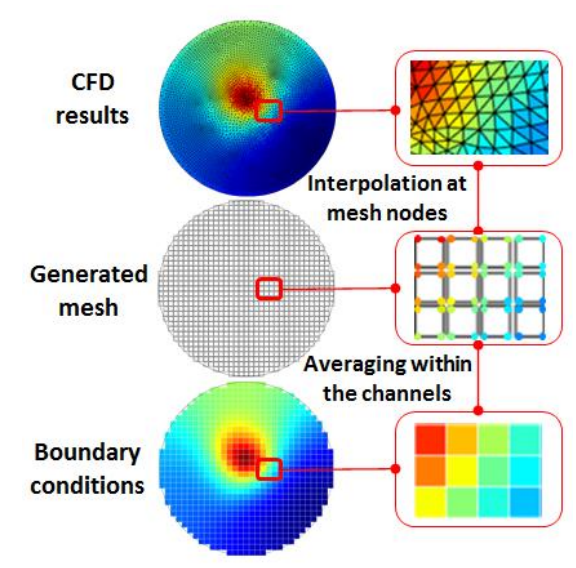

Fig. 2. Calculation of input boundary conditions at catalyst inlet.

\subsection{Catalyst modelling}

The developed multichannel catalyst model utilizes the well-known 1D single-channel approach [12] extended to take into account both heat transfer between the channels and distributions of gas flow parameters at catalyst inlet.

Inside a channel gas properties are calculated as functions of axial distance:

$$
\begin{gathered}
\frac{\partial T_{g}}{\partial z}=-\frac{h P}{\rho_{g} A_{g} C_{p, g} u}\left(T_{g}-\overline{T_{w}}\right) \\
A_{g} u \frac{\partial C_{i}}{\partial z}=s \sum_{j} R_{j, i}
\end{gathered}
$$

where $T_{g}, \rho_{g}, C_{p, g}$ - gas temperature, density and specific heat capacity, respectively; $u-$ gas velocity; $\overline{T_{w}}-$ averaged channel wall temperature; $P$ - cross section perimeter, $A$ - cross section area; $C_{i}$ - concentration of the i-th component; $R_{j}$ - reaction rate of $\mathrm{j}$-th reaction; $s-$ number of reaction sites per channel's length; $\mathrm{z}$ - axial coordinate.

The Eley-Rideal mechanism was used to describe catalytic reactions. In this study only four dominant reaction pathways were considered:

Ammonia adsorption:

$$
\mathrm{NH}_{3}(g) \rightarrow \mathrm{NH}_{3}(s)
$$

Ammonia desorption:

$$
\mathrm{NH}_{3}(s) \rightarrow \mathrm{NH}_{3}(\mathrm{~g})
$$

Ammonia oxidation:

$$
4 \mathrm{NH}_{3}(s)+3 \mathrm{O}_{2} \rightarrow 6 \mathrm{H}_{2} \mathrm{O}+2 \mathrm{~N}_{2}
$$

Nitric oxide reduction:

$$
4 \mathrm{NH}_{3}(s)+4 \mathrm{NO}+\mathrm{O}_{2} \rightarrow 6 \mathrm{H}_{2} \mathrm{O}+4 \mathrm{~N}_{2}
$$

Reaction rates were computed as follow:

$$
\begin{gathered}
R_{a d s}=k_{a d s} C_{N H 3}(1-\theta) \\
R_{d e s}=k_{d e s} \exp \left(-\frac{E_{a, d e s}(1-\alpha \theta)}{R T_{w}}\right) \theta \\
R_{\text {oxid }}=k_{\text {oxid }} \exp \left(-\frac{\left.E_{a, o x i d}\right)}{R T_{w}}\right) \theta \\
R_{\text {red }}=k_{\text {red }} \exp \left(-\frac{\left.E_{a, \text { red }}\right)}{R T_{w}}\right) C_{N O} \theta
\end{gathered}
$$

The change of ammonia fractional loading onto the catalyst surface was calculated with the equation:

$$
\frac{\partial \theta}{\partial t}=\frac{1}{\Omega} \frac{\partial C_{N H 3}(s)}{\partial t}=\left(R_{\text {ads }}-R_{\text {des }}-R_{\text {red }}-R_{\text {oxid }}\right)
$$

where $\Omega$ - number of reaction sites per volume of washcoat.

Kinetic parameters in the reaction rates equations depend on catalyst characteristics and are defined by experimental studies [18-20].

The temperature of catalyst substrate varies both in radial and axial directions. It is governed by the transient heat conduction equation:

$$
\rho_{w} C_{p, w} \frac{\partial T_{w}}{\partial t}=\operatorname{div}\left(\lambda_{w} \nabla T_{w}\right)
$$


where $\lambda_{w}, \rho_{w}, C_{p, w}$ - thermal conductivity, density and specific heat capacity of the substrate material, respectively.

The outer wall of the catalyst is assumed to be thermally insulated. Inside the channels heat is transferred to the walls by convection with the heat transfer coefficient defined based on the semi-empirical correlation [21]:

$$
h=2.976 \cdot \frac{\lambda_{g}}{d_{h}}\left(1+0.095 \frac{\operatorname{Re} \cdot \operatorname{Pr} \cdot d_{h}}{z}\right)^{0.45}
$$

where $\lambda_{g}$ - gas thermal conductivity; $d_{h}$ - channel hydraulic diameter; Re, $\mathrm{Pr}$ - Reynolds and Prandtl numbers, respectively.

The described system of partial differential equations was solved by numerical methods. The space derivatives of the equations $(11,12)$ were approximated by the upwind difference scheme where the catalyst channels were divided in the axial direction into a number of cells with the length of $\Delta z$ (Fig. 3a).

The heat conduction equation (22) was discretized by the control volume method. The catalyst substrate was subdivided into non-overlapping elements in the way shown on Figure 3a.

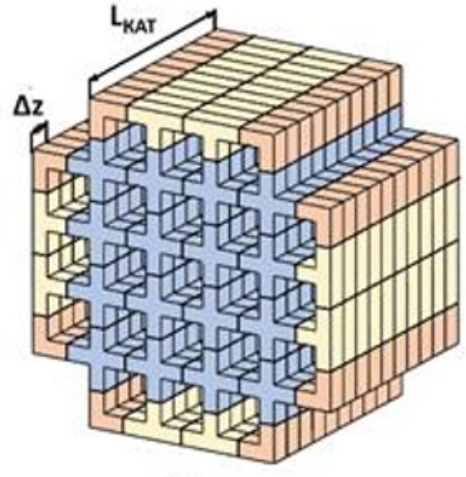

a

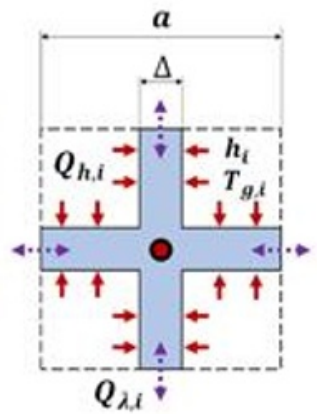

$\mathrm{b}$
Fig. 3. Spatial discretization of the catalyst substrate by control volumes: a - principal scheme of discretization; $b$ - heat flows in a control volume.

For each element the energy balance equation was written (Fig. 3b):

$$
\rho_{w} C_{p, w} V_{j} \frac{d T_{w, j}}{d t}=\sum Q_{h, i}+\sum Q_{\lambda, k}
$$

where $T_{w, j}$ - averaged temperature over $\mathrm{j}$-th control volume; $Q_{h, i}$ - the heat transferred to/from the control volume by convection from/to the gas flowing through the i-th channel (25); $Q_{\lambda, k}$ - the heat transferred to/from the control volume by conduction from/to the k-th adjacent control volume (28).

$$
Q_{h, i}=\frac{T_{g, i}-T_{w, j}}{R_{h, i}+R_{\lambda_{\text {wall }}}}
$$

$$
\begin{gathered}
R_{h, i}=\frac{1}{h_{i} \cdot(a-\Delta) \cdot \Delta z} \\
R_{\lambda_{\text {wall }}}=\frac{2 \cdot 0,785 \cdot \ln (a /(a-\Delta))}{\pi \cdot \Delta z \cdot \lambda_{\text {wall }}}
\end{gathered}
$$

where $T_{g, i}$ - gas temperature inside the i-th channel, $R_{h, i}$ - convection heat-transfer resistance; $R_{\lambda_{\text {wall }}}$ - conduction heat-transfer resistance written for the case of square pipes; $a$ - distance between adjacent control volumes nodes; $\Delta$ - wall thickness.

$$
Q_{\lambda, j-k}=\lambda_{w} \frac{T_{w, k}-T_{w, j}}{a} \Delta \cdot \Delta z
$$

As a result, the time-dependent system of ODEs was derived. It was further solved by the modified Euler method [22].

\section{Model validation}

The UWS droplet evaporation model was validated by experimental data presented in [23]. The authors investigated evaporation characteristics of UWS droplets suspended on a quartz fiber in a stagnant high temperature air environment. A solution of $32.5 \%$ urea by weight was used. A variety of initial droplet diameters and ambient temperatures were considered. As a result, temporal changes in diameters of evaporating droplets were derived (Fig. 4).

In ANSYS Fluent numerical simulations reproducing experimental studies [23] were performed. The corresponding evaporation rates of UWS droplets were received and compared with the experimental ones (Fig. 4). The reasonable match between simulation and experimental data was obtained.

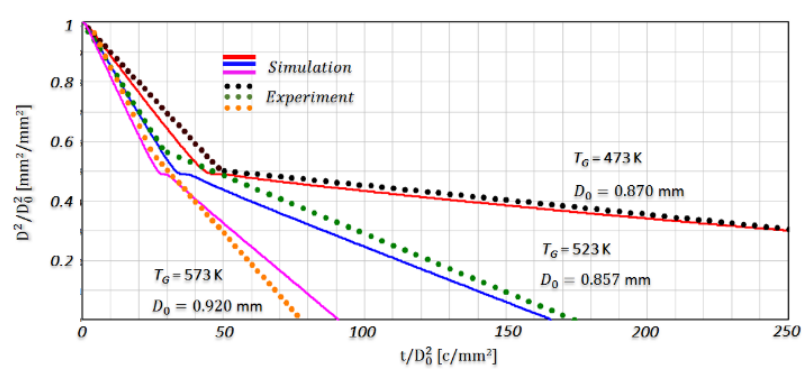

Fig. 4. Comparison of results of numerical and experimental studies on single UWS droplet evaporation.

To validate the injection model, results of experimental measurements of spray characteristics published in [24] were used. The simulation of water spray propagation in air flow passing through the circular duct was performed. Initial drop size distribution, velocity and injection angle were taken from the experimental data. The numerical predictions of spray widths at $100 \mathrm{~mm}$ from the nozzle exit under different gas flow conditions were compared with experimental ones (Table 2). The calculated and 
measured values agreed well confirming the reliability of the spray model

Table 2. Comparison of results of numerical and experimental studies on water injection.

\begin{tabular}{|c|c|c|c|c|}
\hline \multicolumn{5}{|c|}{ Spray width } \\
\multicolumn{1}{|c|}{}
\end{tabular}

To adjust and verify mathematical model of UWS thermal decomposition ( 7 - 10), numerical simulations were carried out and results were compared with experimental data [24]. The computational domain represented an insulated circular duct at the entrance to which hot air was supplied at various speeds and temperatures (Fig. 5). In the centre of the duct, the UWS was injected in the direction of the gas flow. At 3 monitoring planes, placed $3 \mathrm{~m}, 4.5 \mathrm{~m}, 6 \mathrm{~m}$ away from the duct inlet, ammonia conversion efficiency was calculated and compared with experimental values (Fig. 5). The obtained acceptable agreement of the results indicates the adequacy of the adopted model settings.

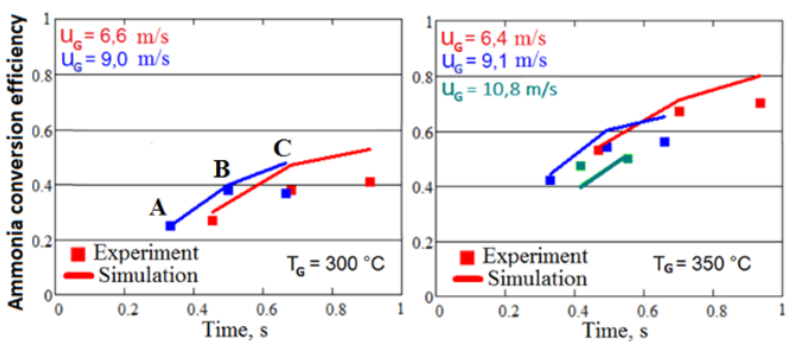

Fig. 5. Comparison of results of numerical and experimental studies on UWS thermal decomposition.

The reliability of the mathematical description of the SCR catalytic chemical reactions was evaluated through comparative analysis of the calculated and experimental data on catalyst NOx conversion efficiency. The latter were taken from the literature [25] where the catalyst sample was investigated. It was placed into a cylindrical quartz reactor supplied by the synthetic gas the chemical composition and temperature of which were varied during the experimental studies. At the outlet from the catalytic unit, the residual concentrations of NO were measured. Using the presented catalyst mathematical model, numerical experiments similar to laboratory ones were carried out. The obtained results were analyzed against the experimental data (Fig. 6). The reasonable match was observed.

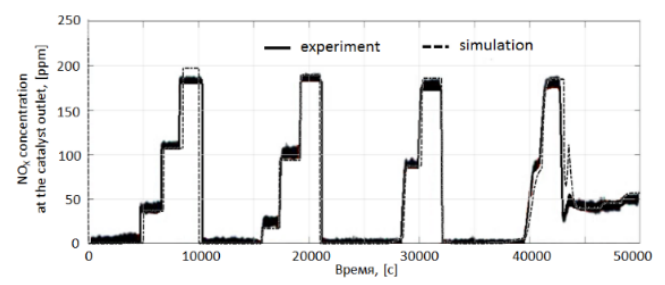

Fig. 6. Comparison of results of numerical and experimental studies on NO reduction.

\section{Results and discussion}

To assess the capabilities of the presented numerical model the simulations of the SCR system (Fig. 7) were performed where the effect of the UWS injection direction on catalyst reduction efficiency was evaluated.

During the first simulation step CFD modelling of gas flow dynamics throughout the SCR system and the UWS injection were performed.

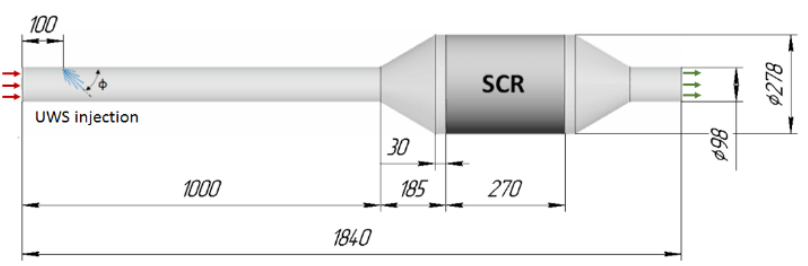

Fig. 7. Computational domain.

The computational domain consisted of the heatinsulated mixing pipe followed by an SCR catalyst. The hot gas was supplied at the pipe inlet with mass flow rate of $0.06 \mathrm{~kg} / \mathrm{s}$, temperature of $665 \mathrm{~K}$ and following chemical composition: $0.03 \mathrm{~mol} / \mathrm{m}^{3}$ of $\mathrm{NO}, 3.5 \mathrm{~mol} / \mathrm{m}^{3}$ of $\mathrm{O}_{2}, 0,9 \mathrm{~mol} / \mathrm{m}^{3}$ of $\mathrm{H}_{2} \mathrm{O}, 1 \mathrm{~mol} / \mathrm{m}^{3}$ of $\mathrm{CO}_{2}$ and $\mathrm{N}_{2}$ as a carrier.

The UWS injection was in the direction of the gas flow at the specific angle (Fig. 7). In this study 3 values were investigated: $45^{\circ}, 70^{\circ}, 90^{\circ}$. The initial droplet size distribution, velocity and spray angle were taken from the experimental work [26]. The mass flow rate of the UWS was $0.000291 \mathrm{~kg} / \mathrm{s}$.

To avoid the detailed discretization of the catalyst substrate during the CFD modeling, it was approximated as a porous media. Pressure losses were taken into account by setting inertial and viscous resistance terms.

As the results, the distributions of gas flow parameters at catalyst inlet at 3 UWS injection angles were obtained. Ammonia molar concentration, gas velocity and temperature profiles are shown on Figure 8. 


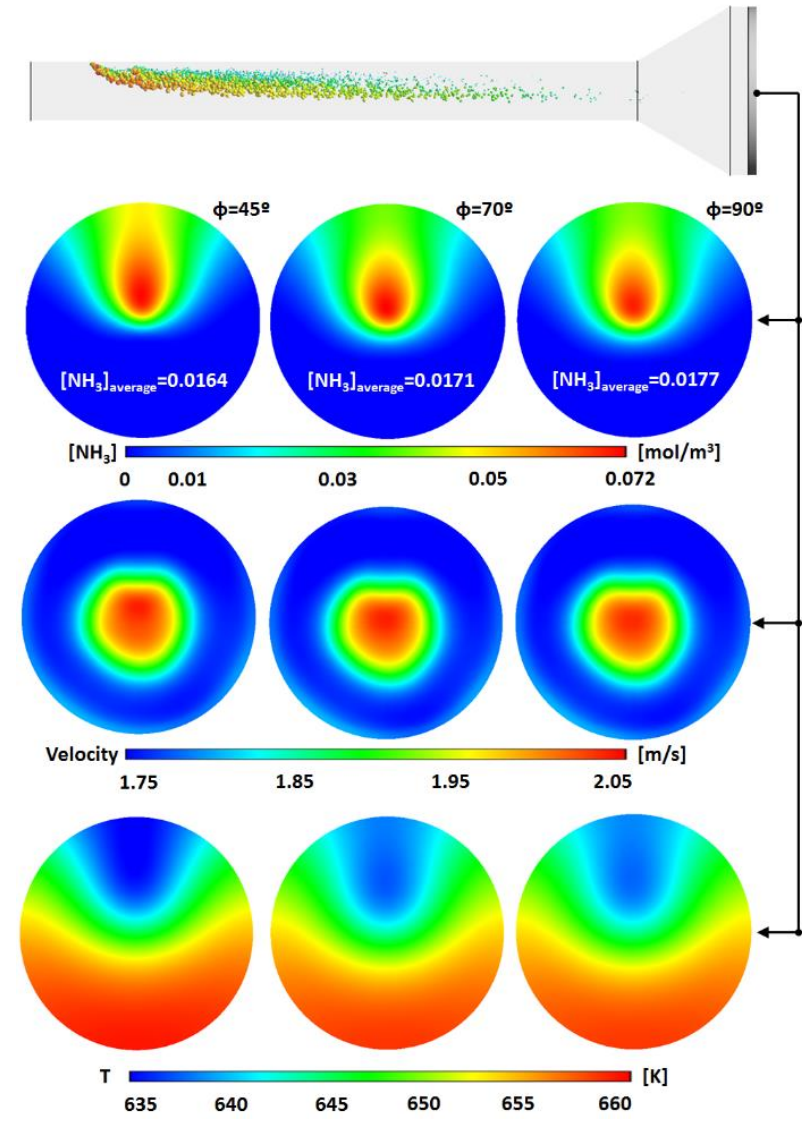

Fig. 8. Distribution of gas flow parameters at catalyst inlet at different UWS injection angles.

The obtained CFD results were further exported to MATLAB where the NOx reduction in the SCR catalyst was calculated using the developed in-house code. The kinetic parameters in the equations $(17-20)$ were taken from [25] for $\mathrm{Cu}$-zeolite catalyst.

For three cases, corresponding to different UWS injection angles, changes in $\mathrm{NO}$ concentration along the catalyst length as well as the overall NO reduction efficiencies were obtained and compared (Fig. 9).

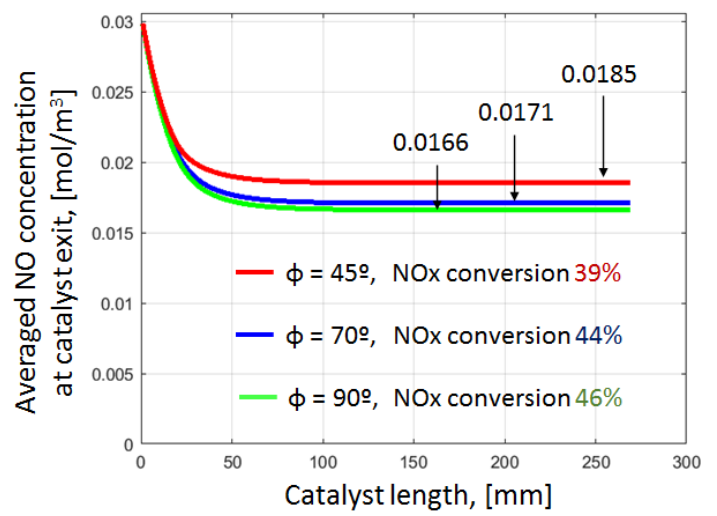

Fig. 9. The change in average NO concentration along the SCR catalyst at different UWS injection.

The results showed a slight increase in the $\mathrm{NO}_{\mathrm{X}}$ conversion efficiency with an increase in the injection angle, that can be explained by the growth of the $\mathrm{NH}_{3}$ concentration at the catalyst inlet. The latter is due to the intensification of the UWS atomization process, which leads to faster evaporation and decomposition of the urea.

The relatively low level of the overall NOx conversion efficiency, that did not exceed $50 \%$, is due to both incomplete decomposition of urea and maldistribution of gas flow parameters at the catalyst inlet. The former caused by the insufficient time for completion of the hydrolysis reaction (9) and the latter one by the geometrical features of the considered SCR system. This led to the fact that $\mathrm{NO}_{\mathrm{X}}$ reduction mostly took place only in a small section of the catalyst whereas in the rest part of it the concentration of NO almost did not changed (Fig. 10).

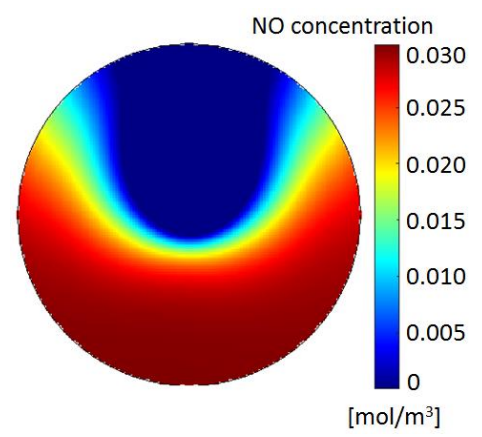

Fig. 10. Contours of NO concentration at the catalyst outlet.

Significant improvement in SCR system performance can be achieved by the installation of static mixers that enhance UWS atomization and the flow mixing [27]. But this was out of this research.

\section{Conclusions}

A methodology for calculating SCR systems combining the advantages of using rigorous $3 \mathrm{~d}$ CFD models and simplified catalyst models has been developed and realised on the example of coupling of ANSYS Fluent with the developed catalyst model implemented in MATLAB. The efficiency of the suggested approach has been confirmed by the fulfilment of numerical simulations of an SCR system where the effect of UWS injection angle on $\mathrm{NO}_{\mathrm{X}}$ reduction performance was investigated. It was found that the increase of UWS injection angle can slightly enhance the NO conversion efficiency due to the intensification of evaporation and decomposition of urea.

\section{References}

1. J. Zhao, L. Grekhov, X. Ma, and A. Denisov, Appl. Therm. Eng. 179, 115699 (2020)

2. J. Zhao, L. Grekhov, and P. Yue, Int. J. Automot. Technol. 21, 649 (2020) A. Kuznetsov, S. Kharitonov, and V. Ryzhov, J. Eng. Gas Turbines Power 140, (2018)

3. V. G. Kamaltdinov, V. A. Markov, I. O. Lysov, A. A. Zherdev, and V. V. Furman, Energies 12, 2643 (2019) 
4. V. A. Markov, S. N. Devyanin, and V. G. Kamaltdinov, in Lect. Notes Mech. Eng. (Springer, 2020), pp. 845-853

5. F. B. Barchenko and V. N. Bakulin, J. Eng. Phys. Thermophys. 90, (2017)

6. A. Joshi, in SAE Tech. Pap. (SAE International, 2020), pp. 2479-2507

7. T. Johnson and A. Joshi, SAE Int. J. Engines 11, 1307 (2018)

8. C. Sharp, C. C. Webb, G. Neely, M. Carter, S. Yoon, and C. Henry, SAE Int. J. Engines 10, 1697 (2017)

9. F. Posada, S. Chambliss, and K. Blumberg, Int. Counc. Clean Transp. 39 (2016)

10. R. Faltsi and J. Mutyal, in SAE 2006 World Congr. Exhib. (2012), p. 40

11. Z. Abidin, K. Das, and C. Roberts, in SAE Tech. Pap. (2013).

12. C. Depcik and D. Assanis, Prog. Energy Combust. Sci. 31, 308 (2005).

13. J. Chen, H. Yang, N. Wang, Z. Ring, and T. Dabros, Appl. Catal. A Gen. 345, 1 (2008).

14. ANSYS Inc. 2013 ANSYS Fluent Theory Guide 15317

15. P. J. O'Rourke and A. A. Amsden, in SAE Tech. Pap. (SAE International, 1987)

16. V. S. Shirodkar, Front. Heat Mass Transf. 7, (2016)

17. E. Abu-Ramadan, K. Saha, and X. Li, in SAE 2011 World Congr. Exhib. (2011).

18. H. Sjovall, R. J. Blint, and L. Olsson, J. Phys. Chem. C 113, 1393 (2009).

19. J. Y. Kim, G. Cavataio, J. E. Patterson, P. M. Laing, and C. K. Lambert, in SAE Tech. Pap. (SAE International, 2007).

20. X. Song, G. Parker, J. Johnson, J. Naber, and J. Pihl, in SAE Tech. Pap. (SAE International, 2013).

21. I. Nova and E. Tronconi, editors, Urea-SCR Technology for DeNOx After Treatment of Diesel Exhausts (Springer New York, New York, NY, 2014)

22. J. C. Butcher, Numerical Methods for Ordinary Differential Equations (Springer London, London, 2016)

23. T. J. Wang, S. W. Baek, S. Y. Lee, D. H. Kang, and G. K. Yeo, AIChE J. 55, 3267 (2009)

24. J. Y. Kim, S. H. Ryu, and J. S. Ha, in Proc. 2004 Fall Tech. Conf. ASME Intern. Combust. Engine Div. (American Society of Mechanical Engineers, 2004), pp. 165-170

25. H. Na, D. Reed, A. Annaswamy, P. M. Laing, and I. Kolmanovsky, in SAE 2011 World Congr. Exhib. (2011)

26. A. Spiteri, P. Dimopoulos Eggenschwiler, Y. Liao, G. Wigley, K. A. Michalow-Mauke, M. Elsener, O. Kröcher, and K. Boulouchos, Fuel 161, 269 (2015)
27. G. Mehdi, S. Zhou, Y. Zhu, A. H. Shah, and K. Chand, Processes 7, (2019). 